Rev. Latinoam. Psicopat. Fund., V, 4, 7-10

Editorial

\title{
Pierre Fédida (1934-2002)
}

Faleceu em Paris, França, no dia $1^{\circ}$ de novembro de 2002, aos 68 anos, completados no dia 30 de outubro, o Professor Doutor Pierre Fédida. Filósofo, psicólogo, psicanalista, Agrégee em Filosofia e Docteur d'Etat, membro da Association Psychanalytique de France (APF), tendo sido seu presidente (1988). Foi, também, professor da Université Paris 7 - Denis Diderot onde dirigiu a Formation Doctorale de Psychopathologie FondamentalePsychanalyse-Biologie, fundou o Laboratoire de Psychopathologie Fondamentale et Psychanalyse e o Centre du Vivant, membro-fundador da Associação Universitária de Pesquisa em Psicopatologia Fundamental, editor responsável da Revue Internationale de Psychopathologie (Paris, Presses Universitaires de France), membro do Conselho Científico da Revista Latinoamericana de Psicopatologia Fundamental, autor de numerosos artigos e diversos livros em colaboração com outros autores. Escreveu Le concept et la violence (Paris, Union Générale d'Éditions, 1977), Corps du vide et espace de séance (Paris, Jean-Pierre Delarge, 1977), L'Absence (Paris, Gallimard, 1978), Crise et contre-transfert (Paris, Presses Universitaires de France, 1992), Le site de l'etranger. La situation psychanalytique 
(Paris, Presses Universitaires de France, 1995) e Des bienfaits de la dépression. Éloge de la psychothérapie (Paris, Editions Odile Jacob, 2001). Estes livros têm sido traduzidos em diversas línguas e, em português, estão publicados Clínica psicanalítica: estudos (São Paulo, Escuta, 1988), Nome, figura e memória. A linguagem na situação psicanalítica (São Paulo, Escuta, 1988), O sítio do estrangeiro. A situação psicanalítica (São Paulo, Escuta, 1996), Depressão (São Paulo, Escuta,1999), e Dos benefícios da depressão. Elogio da psicoterapia (São Paulo, Escuta, 2002).

Nascido em Lyon, de pai argelino e judeu-sefaradita, o rigoroso pensamento de Pierre Fédida encontra suas raízes mais profundas e marcantes na atividade clínica e em suas manifestações psicopatológicas. Por ser, antes de tudo, um pensador do vivido na clínica, encontrou em Freud os fundamentos mais sólidos de sua posição. Não tendo sido um lacaniano, manteve boas relações com Jacques Lacan e com sua obra. Finalmente, não descuidou do estudo e da compreensão da técnica e da metapsicologia de Sándor Ferenczi - que freqüentemente estava presente em seu pensamento -, Melanie Klein, Bion e Winnicott, que também visitavam seu pensamento sobre a atividade clínica.

As principais influências filosóficas sofridas por Fédida passam, por um lado, por Sócrates, Platão e, menos, por Aristóteles assim como por Husserl, Heidegger e Merleau-Ponty. Vivamente interessado na estética, Pierre Fédida era profundo conhecedor da obra de Paul Klee, a quem dedicou uma pesquisa sistemática, e seu pensamento era marcado pelo de Henri Maldiney, a quem se referia como seu mestre, e pelo de Georges Didi-Huberman, de quem se dizia amigo. Assim, em 1987, ofereceu um brilhante curso na Sociedade Brasileira de Psicanálise de São Paulo - SBPSP sobre o texto A caminho em direção à palavra, de Heidegger.

A filosofia e a estética sempre estiveram, em Fédida, a serviço do pensamento sobre o páthos psíquico e freqüentemente se articulavam à psiquiatria fenomenológica, outra sólida fonte de sua posição. Ludwig Binswanger, com quem estudou e praticou em Zurique, na Suíça, certamente foi a principal influência psiquiátrica sofrida por Fédida, com quem consolidou uma forte disposição para a escuta clínica e para a liberdade de pensamento, tanto própria como da do outro. Essa disposição, talvez a manifestação mais marcante da maneira de Fédida estar no mundo, encontrou fundamento e apoio, também, nos demais psiquiatras alemães - Karl Jaspers, von Gebsattel, Tellenbach - na França, em Eugène Minkowski, Henri Ey, Roland Kuhn e Arthur Tatossian e, no Japão, com Kimura Bin. A influência do pensamento psiquiátrico fenomenológico em Fédida revela-se na coletânea denominada Phénoménologie, psychiatrie et psychanalyse (Paris, Echos-Centurion) que organizou e fez publicar em 1986. 
Uma das questões clínicas que mais interessava Fédida era a contratransferência e sobre esse tema, a respeito do qual escreveu vários trabalhos, ele citava Harold Searles como um interlocutor privilegiado.

Em torno de 1964, quando foi a Brasília e tornou-se amigo do Dr. Luiz Meyer, Pierre Fédida passou a se interessar pelo Brasil e pelo pensamento clínico dos brasileiros e voltou numerosas vezes ao nosso país, primeiro por convite do psicanalista Durval Checchinato, no âmbito do Departamento de Psicologia Médica e Psiquiatria da Faculdade de Ciências Médicas da Universidade Estadual de Campinas - Unicamp e, a partir de 1987, por um grupo de psicanalistas coordenados pelo Dr. Luiz Carlos Menezes, de quem era amigo próximo. A partir dessa vinda, Fédida passou a trabalhar na Sociedade Brasileira de Psicanálise de São Paulo - SBPSP, onde Menezes era o anfitrião, formando-se, também, uma forte ligação entre ele, Manoel Tosta Berlinck e Maria Cristina Rios Magalhães que o hospedaram diversas vezes e com quem ele e outros ilustres psicanalistas trabalharam na Livraria Pulsional - Centro de Psicanálise. Esse intenso e, muitas vezes, prolongado trabalho tinha a forma de seminários clínicos em que fragmentos de casos eram apresentados e pensados por grupos de psicanalistas que se constituíam especialmente para essas ocasiões. Foi aí que o estilo de Fédida se revelou de maneira mais florescente e foi também aí que os que deste trabalho tomaram parte puderam testemunhar a maneira original e produtiva de um homem que respeitava as palavras do outro e fazia delas um recurso rigoroso para sua própria atividade de pensamento. Ia também a Campinas trabalhar com o grupo reunido em torno do Prof. Dr. Mário Eduardo Costa Pereira, na Unicamp.

Fédida esteve no Brasil, pela última vez, em 1998, a convite do Laboratório de Psicopatologia Fundamental do Programa de Estudos Pós-Graduados em Psicologia Clínica da Pontifícia Universidade Católica de São Paulo - PUC-SP e com apoio da Fundação de Amparo à Pesquisa do Estado de São Paulo - FAPESP. Realizou, então, um brilhante seminário sobre depressão que resultou em artigo em co-autoria com Manoel Tosta Berlinck publicado em Psicopatologia fundamental (São Paulo, Escuta, 2000) e em seu último livro Dos benefícios da depressão. Elogio da psicoterapia. Nessa oportunidade trabalhou, também, em seminários clínicos na Sociedade Brasileira de Psicanálise de São Paulo, na Livraria Pulsional e na Unicamp.

Pretendia voltar ao Brasil em 2003 para participar do II Congresso Mundial dos Estados Gerais da Psicanálise, que será realizado no Rio de Janeiro.

A influência de Pierre Fédida na psicanálise praticada no Brasil não termina assim. Diversos ilustres psicanalistas brasileiros, dentre os quais se destacam o Prof. Dr. Mário Eduardo Costa Pereira, o Prof. Dr. José Luiz Caon, o Prof. Dr. Edson Luis André de Sousa, o Dr. Fabio Landa, a Profa. Dra. Maria Helena Fernandes, a Dra. Ivanise Fontes, o Prof. Dr. Nelson da Silva Jr., a Dra. Cristina 
Lindenmeyer Saint-Martin e a Dra. Adriana Campos de Cerqueira Leite realizaram seus doutorados sob sua orientação, na Université Paris 7 - Denis Diderot.

Revela-se, assim, uma concepção peculiar de formação do psicanalista, em que a Universidade ocupa um papel central. Fédida tinha um elaborado pensamento a esse respeito e, por isso, foi trabalhar, desde 1979, na Université Paris 7 Denis Diderot.

Em homenagem a esse pensamento e visando estimular a emergência de jovens autores de textos de psicopatologia fundamental, a Associação Universitária de Pesquisa em Psicopatologia Fundamental criou o Prêmio Pierre Fédida de Ensaios Inéditos de Psicopatologia Fundamental que terá sua quarta edição em 2004.

Pierre Fédida era um espírito inquieto, verdadeiramente universitário e sempre atento com a política. A sua preocupação com o sofrimento humano provocado pelas diversas formas de totalitarismo e pela miséria na África, na Índia e na América Latina freqüentemente estava presente em suas conversas. Acreditava que, no discurso miscigenado e exótico dos psicanalistas brasileiros, encontra-se o futuro da psicanálise. Mas, acima de tudo, dava testemunho de uma grande liberdade de rigoroso pensamento voltada para o pathos psíquico, a respeito do qual dizia não haver um único discurso que pudesse esgotar esse assunto. 